\title{
Research on the Development of Sports Events Community based on Club Teaching Mode
}

\author{
Wenfang Li \\ Xi'an Eurasia University, Xi’an, Shaanxi, 710061
}

Keywords: Club; sports events; community communication

\begin{abstract}
The sports club system was proposed by the Eurasian College. Its purpose is to improve students' interest in sports, cultivate students' sports ability, and integrate internal and external sports training. With the development of Internet technology, the relationship between people and sports communities has become more complex and diverse, and the development of socialization of sports events has become an inevitable trend. This paper studies the socialization of sports events based on the club teaching mode, aiming to create a good atmosphere for students' physical education.
\end{abstract}

\section{Introduction}

In the education and training of college talents, physical education classroom plays an important role. "Sports club system" is a new type of college physical education curriculum that has emerged in recent years. It breaks the routine physical education curriculum and uses modern information technology to strengthen communication between teachers and students and students, and promote various social behaviors. . Based on the club teaching mode, the socialization of sports events is one of the important contents of the current sports community research. It reminds us that we should pay attention to the way of social communication and promote the diversified development of social communication mode.

\section{Research on college physical education under the mode of sports club}

Under the teaching mode of sports clubs, we will use random interviews, questionnaires, etc. to gain an in-depth understanding of students' needs and interests, and build a variety of sports clubs based on the results of the survey. The philosophy is always to be student-centered and as much as possible. To meet the needs of students, to provide students with a variety of sports activities, to continuously improve the quality of college sports environment, to provide students with a good sports experience, improve students' enthusiasm for participating in sports activities, improve the overall quality of college students [1].

With the deepening of quality education, the reform of college physical education curriculum has also been carried out. The new talent training program has emerged continuously. The concept of whole-person education is deeply rooted in the hearts of the people. Teachers should comprehensively consider the students' interest points and the specific situation of students in physical education. The student is the center, changing the outline of the past fixed and dogmatic, and flexibly adjusting the teaching plan according to the actual situation of the teaching. In the past physical education teaching mode, the teaching method was single, the teaching content was rigid, and the physical education teaching was mainly based on simple demonstration and imitation. As a result, students could not interest the physical education curriculum and could not stimulate students' creativity. Teachers should adopt new teaching methods, such as Flipping classrooms, micro-classes, etc., designing an interesting activity plan for the course teaching, re-engaging students' interest in learning, actively guiding students to participate in the course, providing the attraction of the course, and also cooperating with diversified assessment methods, Limited to the traditional fixed written test and ability test, the student's physical ability should be comprehensively investigated. 
The concept of the club physical education model is that all students are the center, the students are the masters of the classroom, the teachers can fully consider the individualized differences of the students, the students' wishes are fully expressed, and the grades of senior, intermediate and junior classes are established. The implementation of the teaching mode can carry out teaching activities according to the students' basic conditions, physical ability and hobbies, satisfying the individual needs of different students, and students can fully express their own style in the class. In the sports club, students and teachers, students and students have strengthened communication and communication, which has improved the cooperation and competitiveness of students. Students have become the protagonists of sports activities. During the activities of the clubs, students are responsible for planning activities. To all aspects of the organization's implementation, including club management and club culture building, teachers only provide guidance and guidance when necessary, and provide students with scientific teaching tasks [2]. The transformation of students and teachers has two main aspects, as follows:

On the one hand, it is the development of students' sports habits and the transformation of roles. According to the results of the school survey, after the implementation of the sports club model, the students' satisfaction with the physical education curriculum has been greatly improved, and the participation of students in the physical education curriculum has reached a new high and remains high. Under the teaching mode of sports clubs, students gradually liked sports activities, and good exercise habits from morning exercise to night running gradually developed, and the mental outlook of students also improved significantly. At the same time, the sports club teaching model has also promoted the construction of campus sports culture. Students have become the protagonists of sports activities. Regularly organized a series of sports activities on campus, students are responsible for all aspects of event planning, personnel organization and activities. Work, such as school-level sports events, school-wide sports games, etc., has created a sports wind on the campus, and Eurasian trait sports have gradually formed.

On the other hand, the teacher's teaching methods and role changes. In the past physical education, teachers were in an active position to teach students unilaterally the sports knowledge, and to demonstrate and imitate. Students passively accepted the theory of sports theory, but only through such teaching methods could not stimulate the enthusiasm and interest of students. . Under the teaching mode of sports clubs, the hierarchical teaching has emerged as the times require, and the teaching methods taught by the teachers in the past have been changed to the guiding teaching methods. The teachers only play the role of guidance and guidance. The students are the protagonists of the classroom, and the teachers can use them. Diversified teaching methods such as micro-course videos are taught to encourage students to participate in sports activities, allowing students to take the initiative to learn and practice, to understand the learning situation of students in the online platform, and to enable students to find themselves through classroom guidance and correction. Learning interest points, continuously improve students' active learning ability, and finally through the organization of activities and other forms, test the students' learning outcomes, improve students' sense of competition, and further stimulate students' interest in learning.

In sports clubs, teachers and students, students and students need to continuously exchange information, such as the dissemination of classroom knowledge, the dissemination of sports competition consultation, etc., should cooperate with external enterprises to develop an appointment system based on the school educational system. In combination, teachers and students can communicate in real time through the online platform. Students can make appointments on the online time, exercise methods, teacher selection, etc., to form a complete student volunteer course selection system, and fully utilize the teaching information technology in the physical education curriculum. Can maximize the satisfaction of the different needs of students, use the various situations of students, and constantly improve the level of information use of teachers [3].

\section{An overview of the socialization of sports events}

At present, there are relatively few studies on the development of socialization of sports events in China. In general, the audience base of the social communication model is the fans, and the unit 
that constitutes the social is the community. Through the mutual connection and external expansion of the various communities, the social communication system of the event is formed [4]. In this process of formation, it is a gradual transition from one person to more people, and finally a number of interactive communities are formed. The relationship between the communities continues to increase the influence of this process.

Sports events, especially large-scale sports events, are the focus of global audiences and important media events around the world. In the context of the Internet age, the relationship between people has become complicated, people are more and more communicated through the Internet, the relationship between people has a crossover, and the spread of sports audiences in the event. Behavior is also more inclined to share and comment. Social media provides a channel for the spread of large-scale sports events, increasing the positive interaction between audiences and sports events, and the audience can diversify in this platform. With the changes in the socialization of the audience, the communication environment of the new media of sports events has gradually changed. Different from the communication mode of one person and one person or multiple people in the past, the communication of sports events has shown a trend of socialization. The community is the core for information dissemination. The common language and value standards of the members of the organization are the necessary conditions for the formation of the community, and the values of social significance are formed between the individuals. In the sports event community, it can meet the different sports needs and social activities of the audience.

\section{The characteristics and strategies of the socialization development of sports events based on the club teaching mode}

\subsection{Demand driven}

During the World Cup in Brazil, according to the information characteristics of netizens and fans on the network platform, Tencent and IBM conducted detailed analysis of the data, grasped the points of interest and needs of the members of the sports community, and pushed hot topics and derivative content according to the needs of users. , constantly improve the popularity of sports events. This shows that the process of sports event communication is gradual, it is a process from the inside out, from the near to the far, first of all to meet the needs of the current audience, improve the current participation in activities, do a certain basic work, target audience The characteristics and needs of the design of the event content, planning and organizing related event activities, promotion and dissemination of activities within the community. At the same time, we must make full use of big data to understand the different needs of community members at different stages.

The audience of sports events is fixed, and its scope is limited. It is scarce resources for fans. Once this information is obtained, the audience will actively display on social media and online platforms and share them with their friends. Therefore, such a way of sharing and feedback in the sports community is also an important means of community communication and promotes the promotion of sports events. Event organizers and media departments should actively pay attention to the internal situation of the community, enhance the interaction between the communities through modern means of communication, timely adjust and improve, continuously stimulate the interest of the audience, and provide content that is more in line with the needs of the audience. Activities with high participation and enthusiasm should be greatly exerted [5].

\subsection{Socialized communication}

After the initial promotion of sports events within the club, the strength of the internal audience of the club should be fully utilized as a seed for wider dissemination and expansion. First of all, we must strengthen the control of the theme and content of the communication, pay attention to the various competitions on the field, and the propagating tendency should be based on entertainment and gamification, and can be carried out by means of quiz and games. For example, Sina's "microblogging kick", Sina invited the participation of major popular stars, real-time coverage of the event hotspots, the results of the shot can be shared to friends with one click, the daily 
participation is up to millions of people, realized on social networks Large-scale communication allows the audience to show higher motivation to participate, continuously expand the size of the community, stimulate the enthusiasm of the audience, and promote the initial integration and development of different communities. In the World Cup in Brazil, various media have adopted the methods of quiz and games to attract the participation of the audience, forming a feast for the entertainment of the whole people, which is not limited to a special event.

In terms of communication channels, there are mainly two forms, namely, online communication and offline communication, online sports events, sharing and interaction of activities, offline activities, and social marketing [6]. . Online should pay attention to the user's media use appeals. The planning of the event should focus on various hotspots and pay attention to user experience and activities. At present, many large-scale sports events pay more attention to offline conversion in the process of communication, and the trend of integration and development is presented online and offline. Online, the main job is the media activities related to the event, including the latest progress notices, press conferences, etc. Sports events in the form of press conferences often ignite some topics, which has gradually become a popular sports event promotion. An important way. Achieve deep integration between online and offline, increase audience participation, promote the efficiency of event communication, attract more people to join the community, and continuously expand the number and scale of the community to ensure the promotion of sports events.

\subsection{System linkage}

The current development of the sports community presents a trend of combining online and offline, but at the same time it is inevitable that a large number of relatively discrete communities will emerge. Conversely, the promotion of the event will be further promoted, and the promotion speed of the community will gradually slow down. . At this time, it is necessary to form an effective system to connect different communities, realize the community crossover and intercommunication of the fan groups, and improve the stickiness of the audience and the community.

First, we must pay attention to the interoperability of the theme. The dissemination of the event should revolve around a fixed topic, which is the content that the audience is interested in. It ensures that the content is universal for the audience, and the sports program should be fixed to resonate with more audiences. But at the same time, we must also pay attention to the fact that we should not be overly aware of the scope of the topic, and should integrate events, stars, events and so on. Second, pay attention to the overlap of circles [7]. Community members may play more than one role and may be involved in multiple communities with different characteristics. Third, the promotion scope and theme setting of sports events should have greater coverage. There are big differences between sports projects. The selection of projects should be based on projects with wide hobbies and world influence, in order to ensure the high popularity of social networks.

\subsection{Community expansion}

The source of the community's communication and the enthusiasm of its members, its strength lies in scalability, the connection between the community and the audience can achieve the growth and development of the community. For the organizers of the event, such a mode of communication has a great advantage, that is, the transmission cost is low, the effect is good, and with the positive guidance, it can induce a large heat in a short time, and a very large recursive effect is generated. For individuals, providing valuable and valuable themed activities, their participation and enthusiasm will increase dramatically. As the size of the community increases, the diversity of community members gradually becomes more prominent, the inherent attributes of the community gradually become blurred, and the sense of belonging of community members gradually decreases, leading to a decline in community cohesion. Community expansion should pay attention to the various needs of the audience and continuously improve the communication efficiency between people [8]. With the promotion of mobile Internet and the establishment of a network platform, social capital has its own nature of profit-seeking, and the explosive effect of information dissemination is increasingly prominent, providing more services for users, closely integrating needs and audiences, and consolidating the foundation of social connections. In order to maximize 
the value of the dissemination, the viscosity of the community users is enhanced.

\section{Conclusion}

With the development of Internet technology, the relationship between people and sports communities has become more complex and diverse, and the development of socialization of sports events has become an inevitable trend. Based on the club teaching mode, the socialization of sports events is one of the important contents of the current sports community research. It reminds us to pay attention to the social communication mode, promote the diversified development of social communication mode, and stimulate students' interest in sports activities. The comprehensive quality of students provides new ideas for college physical education.

\section{Acknowledgements}

Fund Project: the National Social Science Fund Project (13xk8008);

Ministry of Education, "New Century Talents Support Program" (NCET-13-0925)

\section{References}

[1] Wang Zhiqiang, Tang Ling, Hong Xiuyan. Research on the reform and teaching practice of college sports curriculum club system_— Taking Xi'an Eurasian College as an example (modified version) [J]. Caizhi, 2018(22):67.

[2] Chen Wei, Gao Aiguo, Sun Qing. Research on the Reform of Teaching Model of Physical Education Curriculum Club System in Higher Vocational Colleges_-Taking Qingdao Vocational and Technical College as an Example[J]. Journal of Weifang Engineering Vocational College, 2016, 29(01): 90-95.

[3] Zhu Baoping. Research on the "Club-Three-Sex" Mode Teaching of Public Physical Education in Universities in Heilongjiang Province [D]. Mudanjiang Teachers College, 2013.

[4] Tao Xiaobin. Research on the teaching mode of sports clubs in higher vocational colleges in Hunan Province [D]. Hunan Normal University, 2013.

[5] Yang Liu. Analysis of the current situation and reform of the teaching organization form of sports clubs in colleges and universities [D]. Hunan Normal University, 2006.

[6] GOU Fengyun. Investigation and analysis of the current situation of physical education in colleges and universities [D]. Inner Mongolia Normal University, 2006.

[7] Jiang Ling. Theoretical and practical research on the implementation of integrated teaching inside and outside the PE system in colleges and universities [D]. Beijing Sport University, 2004.

[8] ZHOU Yunfei, CHEN Donggang, LIU Jianping. The Choice and Practice of Teaching Models in College Sports Clubs[J]. Journal of Shanghai Physical Education Institute, 2002(04): 86-89.

SPC (Statistical Process Control, SPC) is through the use of techniques such as statistical process.

The Introduction of Control Chart. In the production process, when the influence of the only.

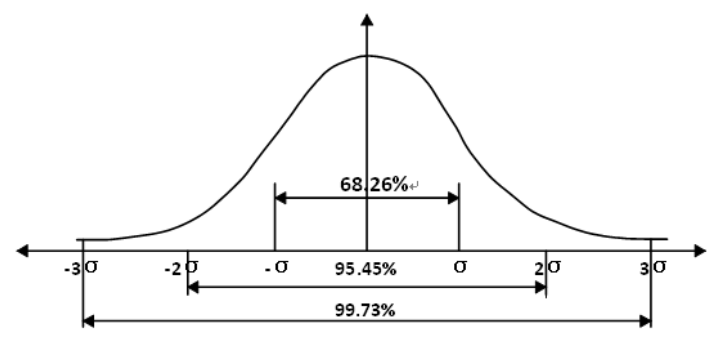

Figure 1. Distribution plot

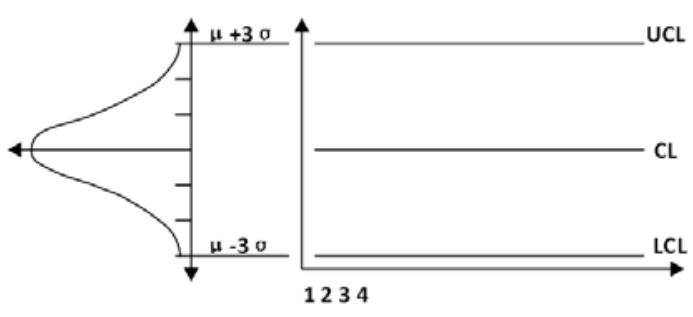

Figure 2. Principle control chart 